IRSTI 44.31 .31

\author{
${ }^{1}$ A. Askarova, ${ }^{2}$ S. Bolegenova, ${ }^{3}$ P. Safarik, ${ }^{1}$ V. Maximov, ${ }^{* 1} \mathrm{M}$. Beketayeva \\ ${ }^{1}$ Scientific Research Institute of Experimental and Theoretical Physics, Almaty, Kazakhstan \\ ${ }^{2}$ Physics and Technical Physics Department, Al-Farabi Kazakh National University, Almaty, Kazakhstan \\ ${ }^{3}$ Thermodynamics and Fluid Dynamics Department, Czech Technical University in Prague, Prague, Czech Republic \\ *e-mail: Beketayeva.m@gmail.com
}

\title{
Heat and mass transfer processes at high-temperature media during combustion of low-grade pulverized coal
}

\begin{abstract}
The article is devoted to the complex research processes of heat and mass transfer occurring in the real conditions of solid fuel (coal) combustion. Development of technological processes with economic and ecological advantages are the main purpose for many researches in thermal physics and technical physics. The complex processes of heat and mass transfer in the presence of combustion are non-stationary, strongly non-isothermal with a constant change in the physical and chemical state of the environment. It greatly complicates their experimental study. In this case, studying of heat and mass transfer in high-reacting media with simulation of physical and chemical processes occur during combustion of pulverized coal is important for the solution of modern power engineering industry and ecology problems. In this regard, a comprehensive study of heat and mass transfer processes at hightemperature media observed. Investigations based on the achievements of modern physics by using numerical methods for 3D modeling. Numerical experiments are conducted to describe and study aerodynamic characteristics, heat and mass transfer processes during the burning of pulverized Kazakhstan low-grade coal. The results obtained are of great practical importance, since they allow us to develop recommendations for the improvement and design of new combustion chambers and burners, and also can be useful in optimizing the whole process of burning fossil fuels.
\end{abstract}

Keywords: aerodynamic, combustion, heat exchange, numerical experiment

\section{Introduction}

Solid fuel combustion is a complex physical and chemical phenomenon, which occurs at high temperatures with rapid and complete oxidation of combustible matter (carbon) by atmospheric oxygen and accompanied by a large amount of heat release [1-2]. Due to the low quality of main Kazakh coal deposits their exploitation at industry has increased scientific and applied relevance. Conducting of deep research on coal combustion in the real conditions can ensure the efficient technological process at all [3-5]. Heightened interest observed in particular to the study of heat and mass transfer processes at combustion of pulverized Kazakh coal with high ash content [6-7]. As it known combustion processes take place under conditions of strong turbulence and non-isothermal flow, multiphase medium with a significant impact of nonlinear effects of thermal radiation, interfacial interaction and multistage proceeding with chemical reactions [8-9]. Such phenomena have an important role in studying of the natural phenomenon of low-grade coal combustion. So investigations of turbulent chemically reacting media are extremely important to deepen knowledge of physical and chemical properties, for application possibilities.

In the context of depletion of natural energy resources and environmental pollution rational use of energy fuel, increasing the efficiency of energy generation and solution of environmental problems are urgent and important task to solve. Development of technological processes with economic and ecological advantages are the main purpose for 
many researches in this area. The complex processes of heat and mass transfer in the presence of combustion are non-stationary, strongly nonisothermal with a constant change in the physical and chemical state of the environment. It greatly complicates their experimental study. In this case, studying of heat and mass transfer in high-reacting media with simulation of physical and chemical processes occur during combustion of pulverized coal is important for the solution of modern power engineering industry and ecology problems. In this regard, a comprehensive study of heat and mass transfer processes at high-temperature media observed. Investigations based on the achievements of modern physics by using numerical methods for 3D modeling [10-15] that in turn do not need labor force also much time. Applying of computational technology allow us to describe the actual physical processes that occur during combustion of energy fuel as accurate as possible. Finally, it has been put the objective of this paper oriented on holding numerical experiments on studying heat and mass transfer processes occurring in the areas of real geometry of the combustion chamber during the burning of energy fuel. It has been established mathematical model of physical-chemical combustion process.

\section{Materials and methods}

Study of processes of heat and mass transfer during coal combustion is possible only based on a complete theory of combustion physics. It includes a wide range of physical and chemical effects and its formulation of a mathematical model. For the simulation of heat and mass transfer in the presence of physical and chemical processes are used the fundamental laws of conservation of mass, momentum, energy [16-19]. Heat and mass transfer processes in the presence of physical and chemical transformations - is the interaction of turbulent flows. Therefore, the chemical processes here should take into account the law of conservation of components of the reacting mixture, multiphase medium, its turbulence degree, heat generation due to the radiation of heated fluid and chemical reactions. The law of conservation of substance written in the form of the law of conservation of matter as follows:

$$
\frac{\partial \rho}{\partial t}+\frac{\partial}{\partial x_{i}}\left(\rho u_{i}\right)=q_{N} .
$$

The law of conservation of momentum and the equation of motion expressed as:

$$
\frac{\partial}{\partial t}\left(\rho u_{i}\right)=-\frac{\partial}{\partial x_{j}}\left(\rho u_{i} u_{j}\right)+\frac{\partial \tau_{i j}}{\partial x_{j}}-\frac{\partial P}{\partial x_{i}}+\rho f_{i} .
$$

Law of energy conservation:

$$
\begin{gathered}
\frac{\partial}{\partial t}(\rho h)=-\frac{\partial}{\partial x_{i}}\left(\rho u_{i} h\right)-\frac{\partial q_{i}^{\text {res }}}{\partial x_{j}}+ \\
+\frac{\partial P}{\partial t}+u_{i} \frac{\partial P}{\partial x_{i}}+\tau_{i j} \frac{\partial u_{j}}{\partial x_{i}}+S_{h}
\end{gathered} .
$$

The conservation law for the components of the reaction mixture:

$$
\frac{\partial}{\partial t}\left(\rho C_{\beta}\right)=-\frac{\partial}{\partial x_{i}}\left(\rho C_{\beta} u_{i}\right)+\frac{\partial j_{i}}{\partial x_{i}}+S_{\beta} .
$$

For technical flames, it takes into account the transfer of matter only by diffusion. Transfer of substance due to the pressure gradient, the action of external forces (electric and magnetic fields) and thermal diffusion are small and they be neglected. Then the last equation written as follow:

$$
\begin{gathered}
\frac{\partial}{\partial t}\left(\rho C_{\beta}\right)=-\frac{\partial}{\partial x_{i}}\left(\rho C_{\beta} u_{i}\right)+ \\
-\frac{\partial}{\partial x_{i}}\left(\frac{\mu_{e f f}}{\sigma_{\beta e f f}} \frac{\partial C_{\beta}}{\partial x_{i}}\right)+S_{\beta}
\end{gathered} .
$$

In this paper for modeling of turbulence flows used the standard k- $\varepsilon$ turbulence model, excluding the effect of lift or "twist" of flow, which is represented by the equation of turbulent kinetic energy transfer:

$$
\begin{gathered}
\frac{\partial(\bar{\rho} k)}{\partial t}=-\frac{\partial\left(\bar{\rho} u_{j} k\right)}{\partial x_{j}}+ \\
+\frac{\partial}{\partial x_{j}}\left[\frac{\mu_{e f f}}{\sigma_{k}} \frac{\partial k}{\partial x_{j}}\right]+P-\bar{\rho} \cdot \varepsilon
\end{gathered}
$$

And the equation of dissipation (turbulent kinetic energy conversion into internal) turbulent kinetic energy $\varepsilon$ : 


$$
\begin{aligned}
\frac{\partial(\bar{\rho} \boldsymbol{\varepsilon})}{\partial t}= & -\frac{\partial\left(\bar{\rho} \bar{u}_{j} \varepsilon\right)}{\partial x_{j}}+\frac{\partial}{\partial x_{j}}\left[\frac{\boldsymbol{\mu}_{e f f}}{\sigma_{\varepsilon}} \frac{\partial \varepsilon}{\partial x_{j}}\right]+ \\
& +C_{\varepsilon, 1} \cdot \frac{\varepsilon}{k} \cdot P-C_{\varepsilon, 2} \cdot \frac{\varepsilon^{2}}{k} \cdot \bar{\rho}
\end{aligned}
$$

Here the kinetic energy production:

$$
P=\left[\boldsymbol{\mu}_{t u r b} \cdot\left(\frac{\partial \bar{u}_{i}}{\partial x_{j}}+\frac{\partial \overline{u_{j}}}{\partial x_{i}}\right)-\frac{2}{3} \cdot \rho \cdot k \cdot \delta_{i j}\right] \cdot \frac{\partial \bar{u}_{i}}{\partial x_{j}}
$$

And the rate of dissipation of turbulent energy:

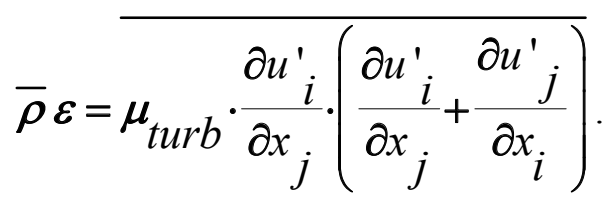

If $\mathrm{k}$ and $\varepsilon$ are known, the turbulent viscosity determined by the Prandtl-Kolmogorov relationship as: $\mu_{\text {turb }}=c_{\mu} \rho \frac{k^{2}}{\varepsilon}$.

Empirical constants $c_{\mu}=0.09 ; \sigma_{k}=1.00 ; \sigma_{\varepsilon}=$ $1.30 ; \quad C_{\varepsilon 1}=1.44 ; \quad C_{\varepsilon 2}=1.92$ determined experimentally. For the turbulent numbers of Prandtl and Schmidt were taken as 0.9.

A generalized equation of the transport value in a turbulent flow will then be:

$$
\begin{aligned}
& \frac{\partial}{\partial t}(\rho \Phi)=-\frac{\partial}{\partial x_{j}}\left(\rho u_{i} \Phi\right)+ \\
& +\frac{\partial}{\partial x_{j}}\left[\Gamma_{\varphi, \text { eff }} \frac{\partial \Phi}{\partial x_{j}}\right]+S_{\varphi}
\end{aligned}
$$

High-temperature media emits heat during combustion. As a result this thermal energy is transformed into radiant energy on the surface of the heated body. Thus, in the heat and mass transfer studies in the presence of combustion in the energy equation (i.e. heat transfer) should be considered the heat exchange by radiation too. On the heat exchange by radiation has a major influence of the water vapor and carbon dioxide. In modeling of flows heat exchange by radiation can be treated at temperatures $500 \mathrm{~K}<\mathrm{T}<2000 \mathrm{~K}$ in the region of the visible and infrared parts of the spectrum. The emissivity of the gas mixture consists of components emissivity, and depends on the partial pressure, temperature and wavelength.

To determine the intensity of the radiation used the six-flow model in this study [20]. It allows approximating the intensity of the radiation with the help of the wall rows by the solid angle:

$$
\begin{gathered}
I=A_{x}(\vec{i} \Omega)+A_{y}(\vec{j} \Omega)+A_{z}(\vec{k} \Omega)+ \\
+B_{x}(\vec{i} \Omega)^{2}+B_{y}(\vec{j} \Omega)^{2}+B_{z}(\vec{k} \Omega)^{2}+\ldots \ldots .
\end{gathered}
$$

This model has been used in the calculation of radiation heat transfer in combustion chambers and showed good agreement with the experimental data.

Physical and chemical processes occurring in the combustion chamber are rapid and complete processes of oxidation of the fuel (in this case highash content coal) take place at high temperatures, accompanied by a large release of energy due to chemical reactions and changes in the concentrations of all substances interact. To describe real physical transformations that occur during combustion of fuel, it is necessary to choose an adequate numerical model [21-24] of physical process. Chemical reactions, which in turn determines the source terms in the equations for energy and the substance components. In this paper adopted a chemical model, which takes into account only the key components of the reaction. A Mitchell-Tarbell model [25] is used, which takes into account the rank of coal for modeling nitrogencontaining components (in this case for the Kazakh coal ash content is $35.1 \%$ ).

It was used one-step model of pyrolysis, when the change in the concentration of carbon described by the ordinary differential equation:

$$
\begin{gathered}
\frac{d c}{d t}=-k_{p y r} c, \\
k_{p y r}=k_{0 p y r} T^{n} e^{-E_{p y r} / R T} .
\end{gathered}
$$

The rate of combustion of volatiles $\omega_{V o l}$ associated with the energy of turbulence $\mathrm{k}$ and its dissipation $\varepsilon$. For areas with a small amount of fuel and sufficient content of oxidizer, it have:

$$
\omega_{1 V o l}=c_{1} \bar{c}_{V o l} \frac{\varepsilon}{k}
$$


For areas with sufficient amount of fuel reaction rate is determined by the stoichiometry coefficient $v_{\mathrm{O}_{2} \mathrm{VOl}}$ :

$$
\omega_{2 V o l}=C_{2} \frac{\bar{c}_{02}}{v_{O_{2} V o l}} \frac{\varepsilon}{k} .
$$

For areas with sufficient fuel and oxidant:

$$
\omega_{3 \mathrm{Vol}}=\mathrm{C}_{3 \mathrm{Vol}} \frac{{ }^{{ }^{\mathrm{CO}_{2}}}{ }^{+\bar{c}_{\mathrm{H}} \mathrm{O}}}{{ }_{\mathrm{O}_{2} \mathrm{Vol}}+1} \frac{\varepsilon}{k} .
$$

From these three speed, the minimum speed of volatile combustion in the actual process is established:

$$
\omega_{V o l}^{*}=\min \left(\omega_{1 V o l}, \omega_{2 V o l}, \omega_{3 V o l}\right) .
$$

where $\mathrm{C}_{1}=4.0, \mathrm{C}_{2}=4.0, \mathrm{C}_{3}=2.0$.

The carbon $\mathrm{C}$ burning rate determined by the diffusion of oxygen into the pores of the solid particles and reactions on its surface:

$$
\begin{gathered}
k_{C}=\frac{k_{C}^{(D)} k_{C}^{(\text {chem })}}{k_{C}^{(D)}+k_{C}^{(c h e m)}}, \\
k_{C}^{(D)}=\frac{2 v_{C} D M_{C}}{R T_{m} d_{P}} .
\end{gathered}
$$

According to the Arrhenius law constant chemical reaction rate will be equal to:

$$
k_{C}^{\text {chem }}=k_{0 C} \exp \left(-E_{C} / R T\right) .
$$

The Mitchell-Tarbell model demonstrates the formation of nitrogen oxides NOx by the oxidation of fuel bound nitrogen. The kinetic scheme takes into account the reaction of the primary pyrolysis, homogeneous combustion of hydro carbonaceous compounds, heterogeneous combustion of coke and formation of nitrogen compounds by thermal and fuel NOx mechanisms. The last ending nitrogen centers considered in this model by subsystem of $\mathrm{CN}$ (HCN, $\mathrm{CN}$ et al.). The most important overall chemical reactions involved in NOx formation during coal combustion hypothesized to be those shown in Figure 1.

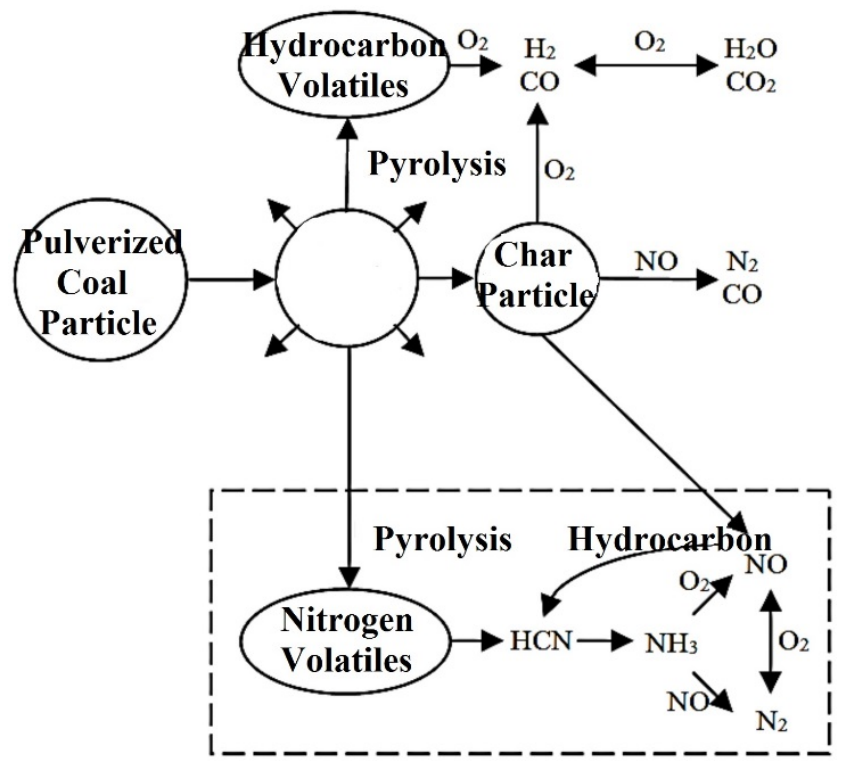

Figure 1 - Schematic Mitchell-Tarbell kinetic model

To avoid mistakes that can lead to a physically meaningless result, an adequate initial and boundary conditions corresponding to real physical process given. As an object of research chosen the combustion process of Kazakh coal in combustion chamber of the real energy facility (boiler BKZ-75 of Shakhtinsk TEC in Kazakhstan). All conditions taken into account of the real process of fuel combustion. For conducting numerical modeling were used control volume method [26-27], where in 
computational experiment the chamber has been divided into 126496 cells.

\section{Results of numerical modelling}

Following shown results of three-dimensional modeling of heat and mass transfer processes during combustion of pulverized low-grade coal in real conditions of combustion chamber of boiler. Aerodynamic pattern of motion of two-phase turbulent flow of pulverized coal combustion causes the heat and mass transfer process in general [2830]. Figure 2 shows a two-dimensional graph of the full velocity vector, determined by the relationship: $\vec{V}=\sqrt{U^{2}+V^{2}+W^{2}}$. In the direction of camera output speed of flows decreased. The peak area values with maximum speed is clearly visible, which is equal to about $20 \mathrm{~m} / \mathrm{s}$. There at 4 meters by height of chamber located the combustor burners, and fed the fuel and oxidant mixture into the camera at maximum speed. Distribution character of flow velocity in height due to the vortex transfer of reacting medium and depending on the geometrical design of the chamber at all. At the outlet of chamber, it seen that velocity has a maximum value $8.76 \mathrm{~m} / \mathrm{s}$ at section $X=7.0 \mathrm{~m}$ and an average value not exceeding the $5 \mathrm{~m} / \mathrm{s}$ by height.

There is a maximum perturbation of the turbulence characteristics in the vortex region, which cause the biggest change of velocity (Figure 3 ). Available surroundings of vortical flow in the central region of the combustion chamber are beneficial to the process of burning pulverized coal (heat exchange and mass transfer).

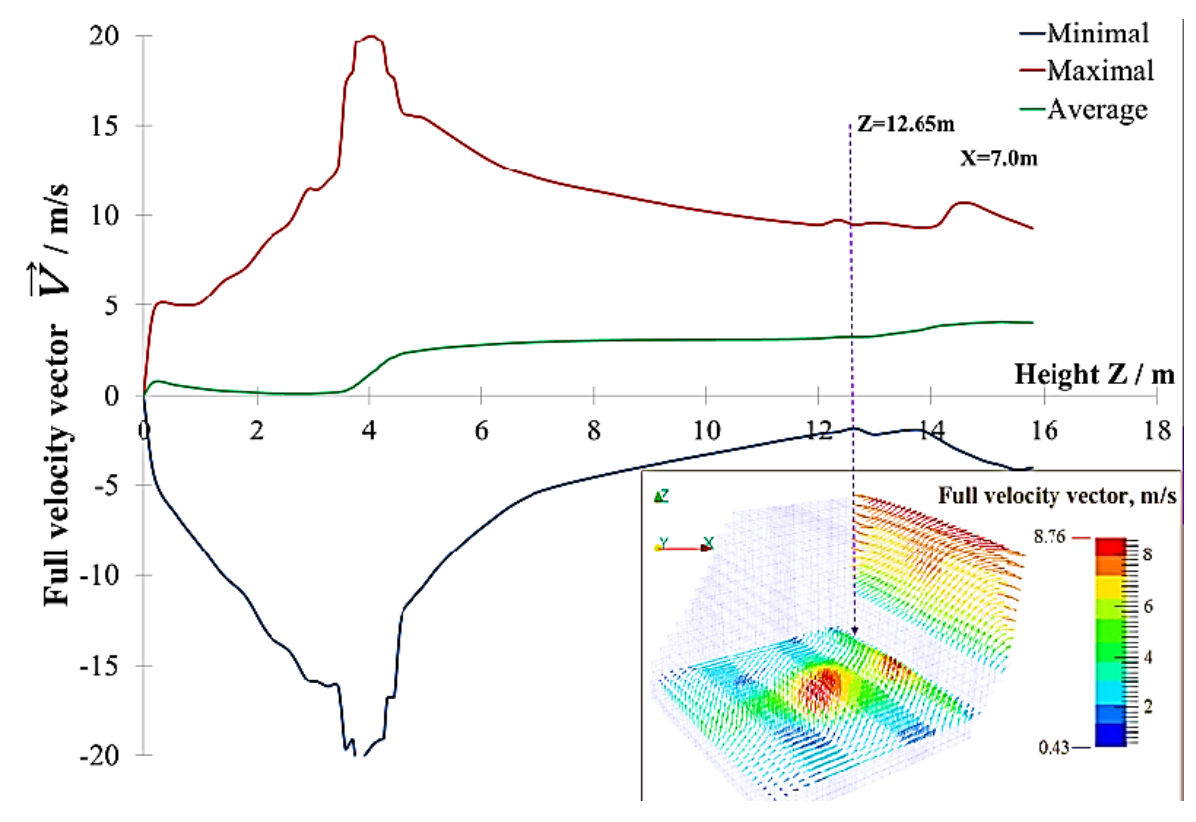

Figure 2 - Distribution of full velocity vector

Figure 4 shows the distribution of maximum, minimum and average values of the temperature field in the combustion chamber. There is also observed a sharp decrease in the temperature of fuel feeding zone. This is because the fuel supplied by a lower temperature. It can be seen that temperature values reach their maximum values in the area below a girdle of the burners where located torch core (approximately at 3 meters). This is because in this area the eddy currents (from installed four burners: on 2 burners on two opposite tiers) have a maximum convective transfer that increases the residence time of coal particles in here. As a result, in this area observed temperature rise to $\sim 1370{ }^{\circ} \mathrm{C}$. In addition, at the output of the chamber maximum value of temperature is about $900-950{ }^{\circ} \mathrm{C}$. This clearly seen from the 3D picture placed in the right corner of the figure. In the figure also presented the point of the theoretically calculated value of the temperature of exhaust gases in the output of the chamber defined according to the normative method of thermal calculation [31] and data from the natural experiments held in real TPP of RK [32]. 


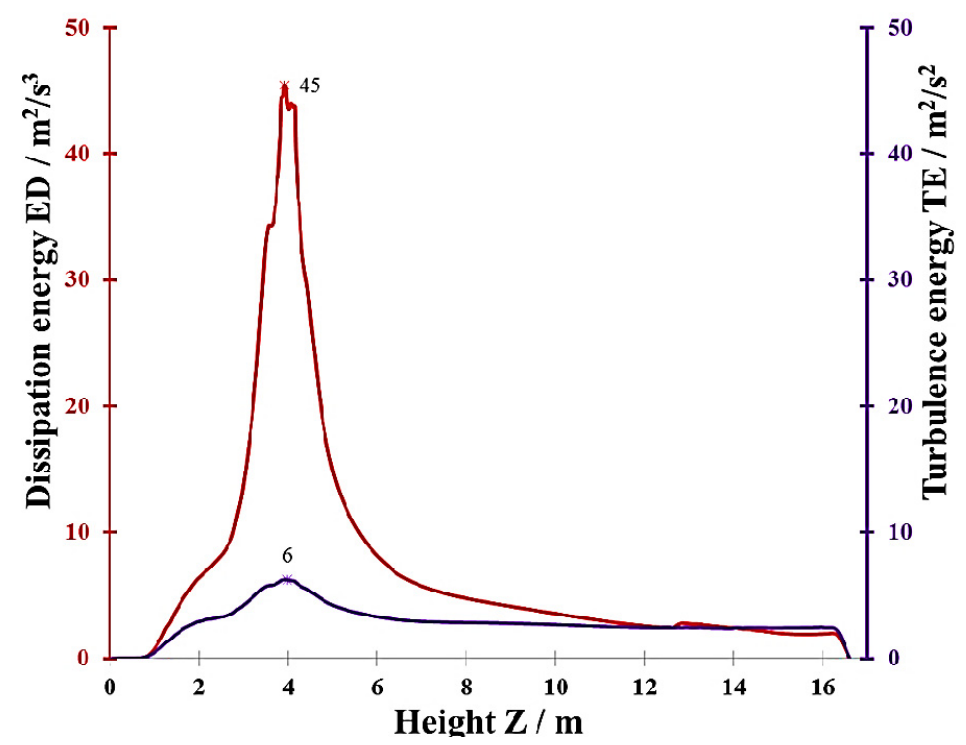

Figure 3-2D distribution of turbulence characteristics

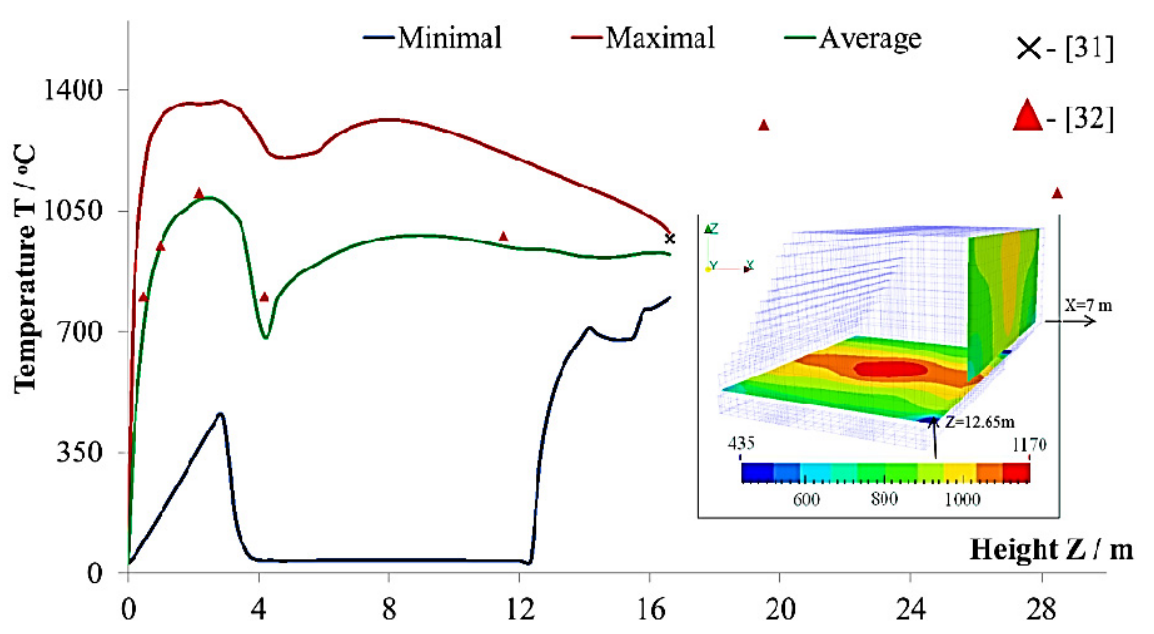

Figure 4 - Distribution of temperature fields and its verification with known data

The method of thermal calculation in power engineering is still the most reliable for finding the temperature at the outlet of the combustion chamber. It is seen that the difference between the results of numerical calculation is small and is only $4.7 \%$. This proves that the method of 3D modeling gives good description of real processes of heat and mass transfer of fuel combustion. The verification results show the good conformity with calculated results.

The following Figure 5, which shows the 3D temperature distribution by the chamber sections, observed the same character as in the previous Figure 4. Temperature values by the height of the combustion chamber monotonically fall. From 3D distribution it is seen that the core of flame is located in the lower part of chamber in the section $\mathrm{Y}=3.19 \mathrm{~m}$. Moreover, there the maximal value of temperature is equal to $1340^{\circ} \mathrm{C}$. Temperature fields are decreased by the height of camera. So temperature has the value in average $940^{\circ} \mathrm{C}$ in section $\mathrm{Z}=12.65 \mathrm{~m}$, when it has $922^{\circ} \mathrm{C}$ at the section $Z=7 \mathrm{~m}$ (the output of chamber). 

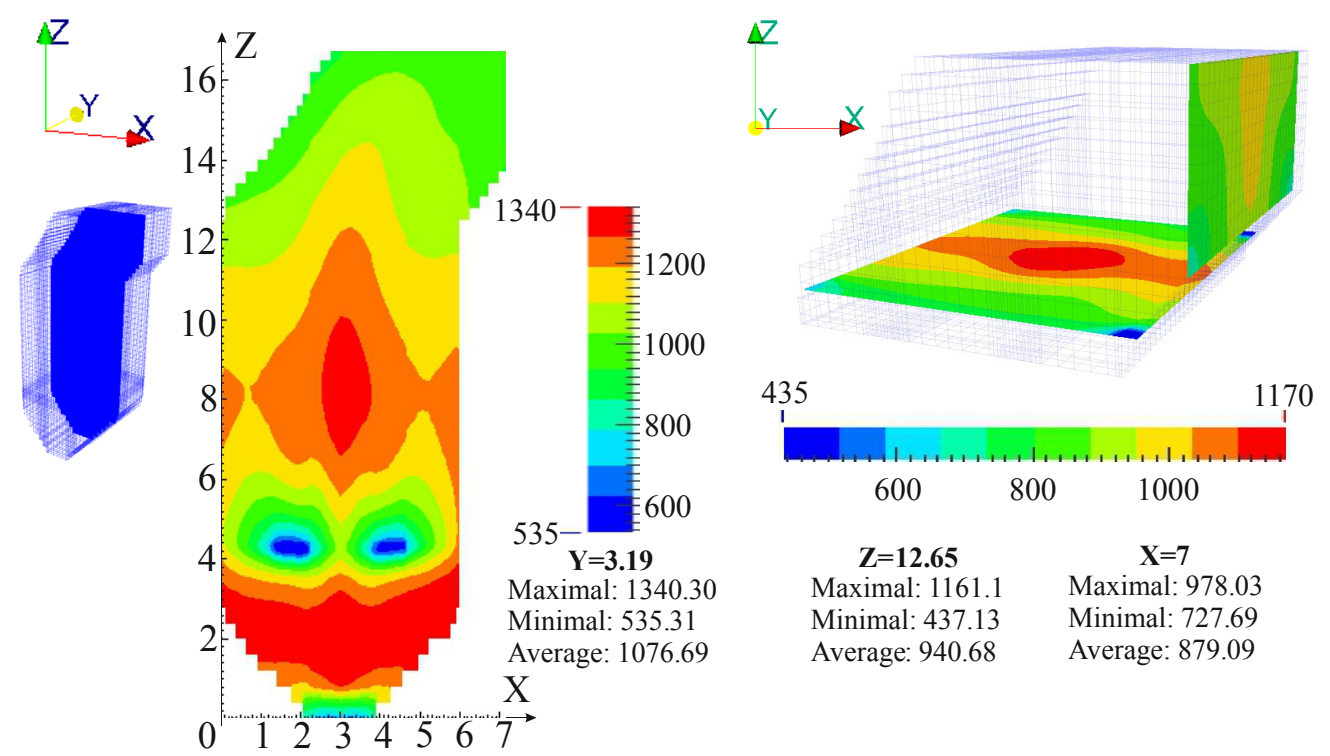

Figure 5-3D temperature distribution by the chamber sections

Below shown the results of 3D modeling of carbon dioxide $\mathrm{CO}_{2}$ and nitrogen oxides NOx concentration distributions. Carbon mono oxide $\mathrm{CO}$ reacts with oxygen completely and so formed its dioxide $\mathrm{CO}_{2}$. Concentrations of carbon dioxide $\mathrm{CO}_{2}$ have their largest amount at the top areas of chamber (section $\mathrm{Y}=3.19 \mathrm{~m}$ ). And the minimal values are observed at the region, where the burner equipment is set. From the figure 6 at the section $\mathrm{Y}=3.19 \mathrm{~m}$ it is seen that concentration of carbon dioxide $\mathrm{CO}_{2}$ has the minimal value equal to $0.0089 \mathrm{~kg} / \mathrm{kg}$. In addition, in average it raised to $\sim 0.13 \mathrm{~kg} / \mathrm{kg}$ at the $\mathrm{Z}=12.65 \mathrm{~m}$ section by height and $\sim 0.15 \mathrm{~kg} / \mathrm{kg}$ at the outlet of the chamber (section $\mathrm{X}=7.0 \mathrm{~m}$ ).
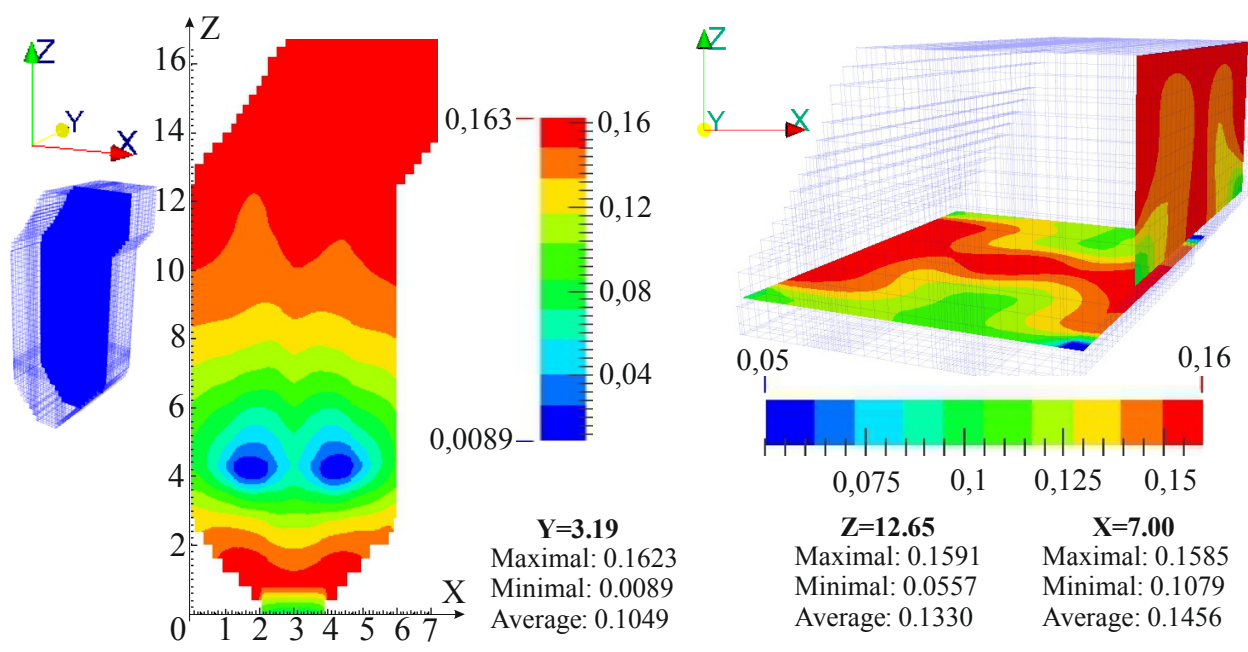

Figure 6 - 3D distribution of the carbon dioxide concentrations on sections of the chamber $\left(\mathrm{CO}_{2}, \mathrm{~kg} / \mathrm{kg}\right)$

Nitrous oxides NOx are formed by seven main nitrous compounds, but because of the small portions of them, except of nitrous mono- NO and dioxides
$\mathrm{NO}_{2}$ (in total NOx), we negligible others. So it could be seen that the maximal amount of nitrous oxides NOx concentrations $0.0109 \mathrm{~kg} / \mathrm{kg}$ presented at the 
burners zone (Figure 7, section $\mathrm{Y}=3.19 \mathrm{~m}$ ). It caused with the fuel-N compound mechanism of NOx formation. Where with height of boiler, it shown decreasing of nitrous oxides concentration. And it has the average value equal to $5.09 \cdot 10-12 \mathrm{~kg} / \mathrm{kg}$ at the output of the combustion volume (section $\mathrm{X}=7.0 \mathrm{~m}$ ).

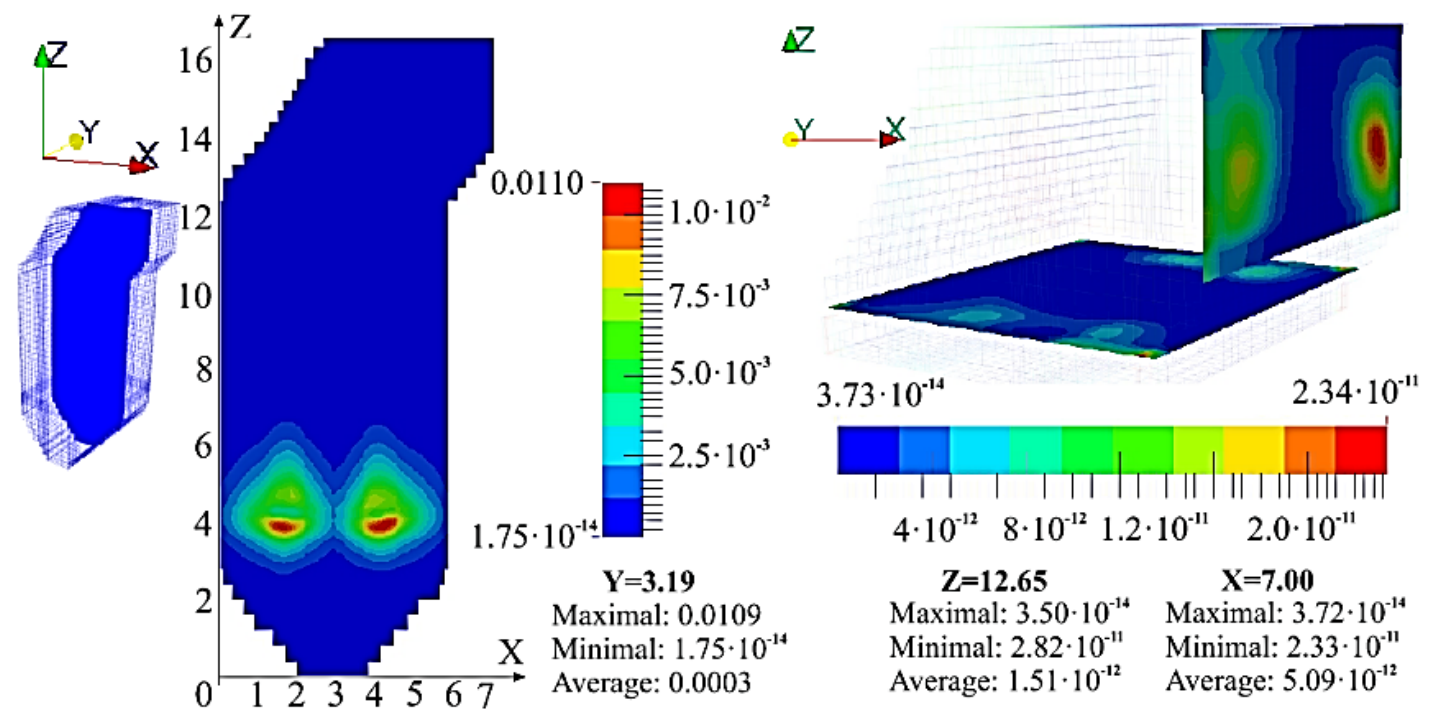

Figure 7-3D distribution of the nitrogen oxides concentrations on sections of the chamber ( $\mathrm{NOx}, \mathrm{kg} / \mathrm{kg}$ )

These concentration distributions of carbon dioxide and NOx verified with the known data as shown in Fig. 8.

Concentrations of carbon dioxide $\mathrm{CO}_{2}$ (a) and nitrogen oxides NOx (b) are in a good agreement with experimental data, received from real thermal power plant equipment [32]. Moreover nitrogen oxides NOx concentrations limit value for Kazakhstan Republic TPP's is given [33]. By comparisons of numerical experiment results held in this work with natural data from TPP, it noticed that the difference is for carbon dioxide $\mathrm{CO}_{2}$ is $4 \%$ and for nitrous oxides $\mathrm{NOx}$ is $5 \%$. So, considering results obtained in this paper we can propose the observed method of research of combustion processes is reliable and valid sufficiently to be useful in studying of low-grade coal combustion technological processes in energy objects.
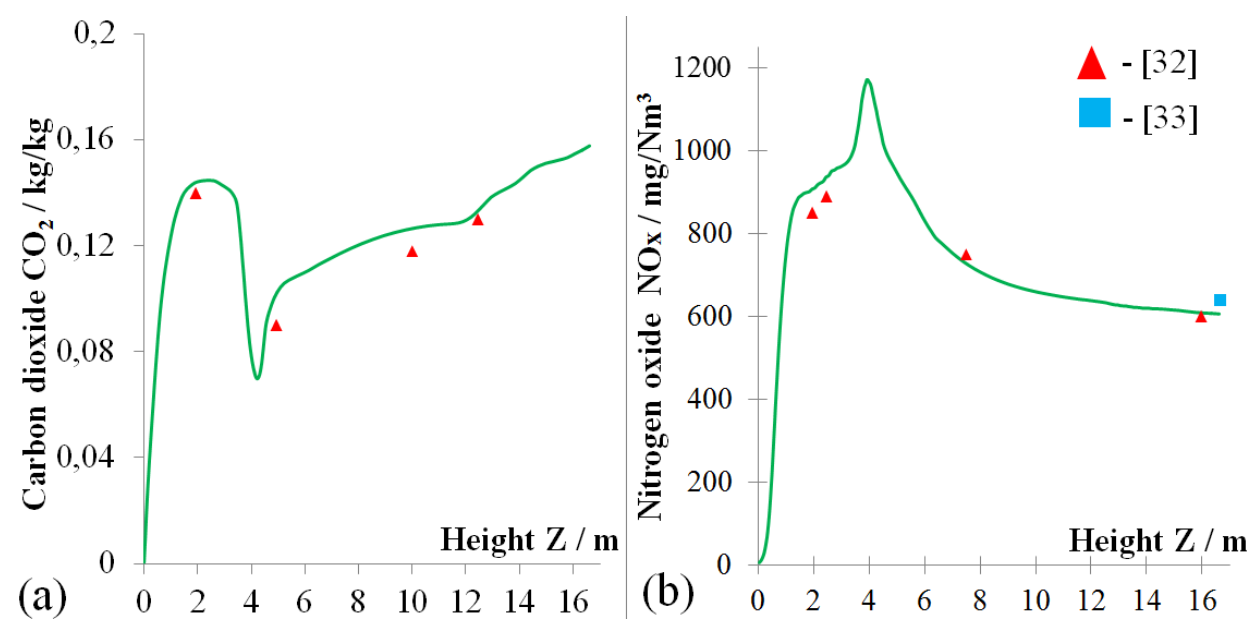

Figure 8 - Verification of calculation results with known data [32, 33] 


\section{Conclusion and perspectives}

In conclusion, with computational research of combustion and modelling of heat and mass transfer processes determined velocity characteristics of turbulent flows, their turbulent kinetic energy and dissipation energy. Aerodynamic characteristics shows that intensive mixing of fuel and oxidant held in the central part of the chamber. In addition, it caused the increasing of temperature values to $1370^{\circ} \mathrm{C}$ in core of torch and monotonically decreased to $922^{\circ} \mathrm{C}$ at the outlet. Formation of hazardous substances as carbon and nitrous oxides $\left(\mathrm{CO}_{2}, \mathrm{NOx}\right)$ are depends on their chemical interaction with oxygen. Carbon dioxide has its maximal values at the outlet of the chamber $(\sim 0.16$ $\mathrm{kg} / \mathrm{kg}$ ), and the nitrous oxides have the maximal amount of $\sim 1200 \mathrm{mg} / \mathrm{Nm}^{3}$ at the burners' zone. Obtained results of numerical experiments have great theoretical and practical importance, as it will allow improve the design of combustion chambers and burners, to optimize the process of burning of high-ash content energy coal of Kazakhstan Republic.

\section{Acknowledgment}

This work supported by the Ministry of Education and Science of the Republic of Kazakhstan under the International Program of subpriority "International Cooperation with China" (MT / 2013-2015).

\section{References}

1. Williams F. Combustion theory. California: Westview Press, 1985. - 704 p.

2. Zarrouk S.J., O'Sullivan M.J., St George J.D. "Modelling the spontaneous combustion of coal: the adiabatic testing procedure." Combustion Theory and Modelling 10, no. 6 (2006): 907-926.

3. Kez V., Consalvi J.L., Liu F., Ströhle, J., Epple, B. "Assessment of several gas radiation models for radiative heat transfer calculations in a three-dimensional oxy-fuel furnace under coal-fired conditions." International journal of thermal sciences. 120 (2017): 289-302.

4. Wu H.D., Han W., Wang D.D., Gao L. "A carbon oxidation factor regression model of coalfired power plants in China." Journal of cleaner production. 142 (2017): 4403-4411.

5. Askarova A.S., Bolegenova S.A., Bolegenova S.A., Maximov V.Y., Beketayeva M.T.
"Influence of boundary conditions to heat and mass transfer processes." International journal of mechanics 10 (2016): 320-325.

6. Askarova A., Bolegenova S., Safarik P., Maximov V., Beketayeva M. "Numerical Modeling of Pulverized Coal Combustion at Thermal Power Plant Boilers." Journal of thermal science 24, no. 3 (2015): 275-282.

7. Askarova A.S., Lavrichsheva Y.I., Leithner R., Müller H., Magda A. "Combustion of low-rank coals in furnaces of Kazakhstan coal-firing power plants." VDI Berichte 1988 (2007): 497-502.

8. Law Ch. K. Combustion Physics. Cambridge: Cambridge University Press, 2006. $742 \mathrm{p}$.

9. Xu W., Kun L. "Analysis of pulverized coal flame stabilized in a 3D laminar counterflow." Combustion and Flame 189 (2018): 106-125.

10. Wieckowski L., Krawczyk P., Badyda K. "Numerical investigation of temperature distribution in the furnace of a coal fired grate boiler in part load conditions." Journal of power technologies 97, no. 5 (2017): 359-365.

11. Askarova A.S., Heierle E.I., Bolegenova S.A., Manatbayev R., Maximov V.J., Beketayeva M.T., Yergaliyeva A.B. "CFD study of harmful substances production in coal-fired power plant of Kazakhstan." Bulgarian Chemical Communications 48 (2016): 260-265.

12. Lazar J., Haugen N., Kruger J., Szlek A. "Numerical Study of Hydrogen Inhibition of Char Gasification Using Detailed Hetero- and Homogeneous Chemical Kinetics." Energy \& fuels 30, no. 6 (2016): 4411-4418.

13. Buchmayr M., Gruber J., Hargassner M., Hochenauer C. "A computationally inexpensive CFD approach for small-scale biomass burners equipped with enhanced air staging." Energy conversion and management 115 (2016): 32-42.

14. Zhao Z.L., Tang H.Q., Quan Q., Zhang J., Shi S. "Simulation Study on Performance of Novel Oxygen-coal Lances for Pulverized Coal Combustion in Blast Furnace Tuyere." Procedia Engineering 102 (2015): 1667-1676.

15. Taraba B., Michalec Z., Michalcova V., Blejchař T., Bojko M., Kozubková M. "CFD simulations of the effect of wind on the spontaneous heating of coal stockpiles." Fuel 118 (2014): 107-112.

16. Muller H. Numerische Simulation von Feuerungen. Braunschweig: IWBT, 1997. -8 p. (in German).

17. Leithner R., Müller H. "CFD Studies for Boilers." Second M.I.T. Conference on 
Computational Fluid and Solid Mechanics, Cambridge, 2003. - $172 \mathrm{p}$.

18. Launder B., Spalding D. "The numerical computation of turbulent flows." Comp. Meths. Appl. Mech. Eng. 3 (1974): 269-289.

19. El-Mahallawy L., El-Din Habik S. Fundamentals and technology of combustion. Oxford: Elsevier Science: Energy, 2002. - 839 p.

20. De Marco A., Lockwood F. "A new flux model for the calculation of radiation furnaces." $L a$ rivista dei combustibili 29 (1975): 1-13.

21. Choubey G., Pandey K.M. "Effect of variation of inlet boundary conditions on the combustion flow-field of a typical double cavity scramjet combustor." International journal of hydrogen energy 43 (2018): 8139-8151.

22. Adamczyk W.P., Myöhänen K., Hartge E.U., Ritvanen J., Klimanek A., Hyppänen T., Białecki R.A. "Generation of data sets for semi-empirical models of circulated fluidized bed boilers using hybrid Euler-Lagrange technique." Energy 143 (2018): 219-240.

23. Li G., Gu F., Wang T., Yang T., Ball A. "Investigation into the dynamic response of cylinder liners in an IC engine based on a validated finiteelement model." Systems science \& control engineering 5, no. 1 (2017): 56-69.

24. Benard P., Balarac G., Moureau V., Dobrzynski C., Lartigue G., D'Angelo Y. "Mesh adaptation for large-eddy simulations in complex geometries." International journal for numerical methods in fluids 81, no. 12 (2016): 719-740.

25. Mitchell J.W., Tarbell J.M. "A kinetic model of nitric oxide formation during pulverized coal combustion." AIChE Jornal 28 (1982): 302-320.

26. Ali H., Askri E., Ben Nasrallah S. "Comparative study of WSGG and SLW models coupled with control volume finite element method for nongray radiation prediction." International journal of thermal sciences 113 (2017): 73-82.

27. Madejski P., Taler D., Taler J. "Numerical model of a steam superheater with a complex shape of the tube cross section using Control Volume based Finite Element Method." Energy conversion and management 118 (2016): 179-192.

28. Bhuiyan A.A., Karim M.R., Hart J.T., Witt P. J., Naser J. "Investigation of Slot-Burner Aerodynamics with Recessed-Type Nozzle Geometry." Fluids 1, no. 2 (2016): 10.

29. Alekseenko S.V., Anufriev I.S., Glavniy V.G., Krasinsky D.V., Rakhmanov V.V., Salomatov V.V., Shadri E.Y. "Study of 3D flow structure and heat transfer in a vortex furnace." Heat transfer research 47, № 7 (2016): 653-667.

30. Bhuiyan A.A., Amin M.R., Naser J., Islam A.K.M. "Effects of geometric parameters for wavy finned-tube heat exchanger in turbulent flow: a CFD modeling." Frontiers in heat and mass transfer 6 (2015): 013005.

31. Teplovoi raschet kotlov: Normativnyi metod. (Thermal calculation of boilers: Normative method). SPb.: NPO CKTI, 1998. - 256 p.

32. Aliyarov B.K., Aliyarova M.B. Szhiganiye kazakhstanskikh ugley na TES $i$ na krupnykh kotelnykh: opyt $i$ perspektivy. (Combustion of Kazakhstani coal at TPPs and large boiler plants: experience and prospects). Almaty: Gylym ordasy, 2011. - $304 \mathrm{p}$.

33. RND 34.02.303-91 Otraslevaya instruktsiya po normirovaniyu vrednykh vybrosov $v$ atmosferu dlya teplovykh elektrostantsiy i kotel'nykh. (Industry guidelines for the regulation of harmful emissions into the atmosphere for thermal power plants and boilers). Astana: MOOS RK, 2004. 